The motion was put to the meeting and carried unanimously with loud applause.

Major Festing said that, as representing the department, he was sorry he could give no more information than the lecturer had. The Government had not yet announced its intention as to what it would do in the matter. It had lately had many other matters on hand. With regard to the lectures, it was felt that it was hardly fair to continue to ask men of science to give their services gratuitously, and until some arrangement for fees could be made, he thought the lectures would probably remain in abeyance. It would give him pleasure to forward the resolution so unanimously carried to the head of his department as requested.

\section{THE DEVELOPMENT OF BATRACHIANS WITHOUT METAMORPHOSIS}

NETAMORPHOSIS, or the ransition of the animal through an intermediate stage between the ovum and the adult, has hitherto been considered by modern naturalists a special characteristic of the Batrachians amongst the Vertebrates, and as one of the main features which disinguish them from the true Rep tiles, with which they were fomerly united. It is, therefore, surprising to learn, as we do from a recent communication of Dr. Peters to the Royal Academy of Scierices of Berlin, that there are cases in which no such metamorphosis takes place, and the young frog is developed directiy from the egg without showing any signs of what is usually called the "tadpole" stage.

Dr. Peters's noteworthy discovery is based upon observations made by Dr. Bello, Herr Krug, and Dr. J. Gundlach, in Porto Rico, on the development of a West Indian tree-frog-Hylodes martinisensis, which seems to be not uncommon in Porto Rico, and is there generally known by the vernacular term Coqui.

Five years ago Dr. Bello stated ${ }^{1}$ that a tree-frog in Porto Rico called Cogut was remarkable from the fact that the young came out of the eggs in a perfect condition, and fit for life in the air. "In 1870 ," he says, "I observed in a gar den an example of this species upon a liliaceous plant, on which about thity eggs were clustered together in a cotton-wool-like mass; the mother kept close to them as if she intended to incubate. A few days afterwards I found the little frogs from two to three lines long just born, with all their four feet perfectly developed, springing about, and enjoying life in the air. In a few days they attained their full size. This garden is surrounded by walls six feet high, and there is no water in it. The soncalled lily (which appears to be an introduced species of Crintm) always contains a little water in the receptacles, but is not a water-plant."

The translator of these observations rightly remarks that the exclusion of the animal out of the egg was not actually witnessed in this case, and that it was possible even in the short time which elapsed between when the eggs were seen and the young frogs appeared, some metamorphosis might have taken place, especially as the subsequent development seems to have been uncommonly quick.

These short observations of Dr. Bello appear to have attracted the less attention inasmuch as the development of tree-frogs from eggs placed in dry situations in frothy masses had been already observed and described in tropical countries. In $1867 \mathrm{Herr}$ Hensel published some interesting observations on Cystignatzus mystacinus, in the forests of Rio Grande do Sul, ${ }^{2}$ and last year Dr. Peters laid before the Academy of Berlin the extraordinary discoveries of Buchholz concerning the egg-masses of Chiromantis guineensis laid upon trees in Guinea. Be-

a "Zoologische Notizen aus Portorico," in "Der zool. Garten," I 87 , p. 35 Sitz. d. Ges. Nat. Freunde zu Berlin 1867, p. to, and Arch. . Nat. xxiii. pt. $x$, p. 129 .

sides this the development of Alytes obstetricans between the hind-legs of the male in the ordinary way, and, through Herr Weinland's brilliant investigations, the metanorphosis of the young in the dorsal sacs of the females of Opisthodelphys and Nototrent, were facts so generally known that it seemed highly improbable that any Batrachian should be developed without metamorphosis.

Under these circumstances it is of the greatest interest to be able to state that Dr. Bello's information has been fully corroborated by recent observations of Dr. Gundlach and by preparations which he has transmitted to Berlin.

"On May 24, 1876," Dr. Gundlach says, "I heard a singular call like that of a young bird, and went to see what it was. Between two large orange-blossoms I perceived a leaf frog, and on taking hold of it, found $I$ had captured three males and a female of the Cogwi. On putting them into a damp glass, one of the males cuickly placed himself on the female and grasped around her. Not long afterwards she had laid from fifteen to twenty eggs, which, however, mostly soon disappearedperhaps eaten.

"There were subsequenty laid five eggs, round, with a transparent covering, which I ramoved and placed on sone wet slime. The inner yelk, of a whitish or pale strawcolour, contracts a little, and then the tail is seen forming.

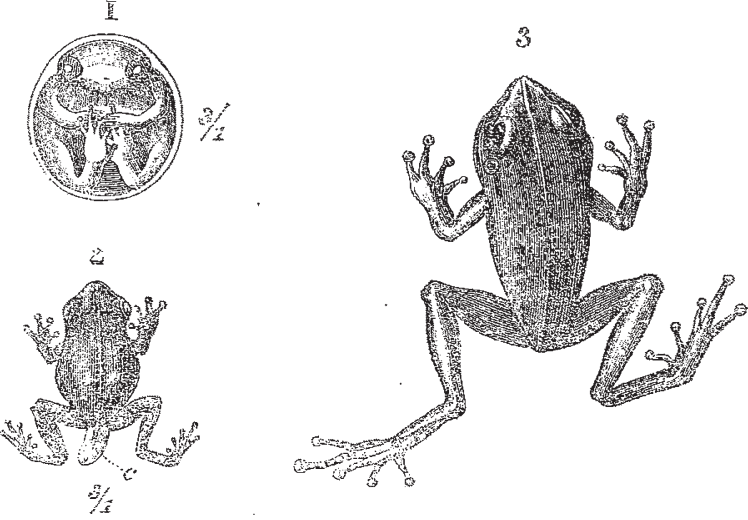

Fic. x.- Egg of Hylodes martiniconsis, twelve days old, lower surface FIG. 2,-Xoung of Hylodes as it leaves the egg; 6 , tail. FIG. 3.-Adult male Hylocles, natural size.

In eight days this was quite clearly visible, as well as the eyes, and the red pulsating blood-vessels. Later on traces of the legs became manifest. I was now absant for some days, and when I returned, on June 6, found the eggs still, but on the next morning, the young were out, and had no trace left of the tail.

"Afterwards I found between two leaves of a large Amaryllid, just like Dr. Bello, a batch of more thar twenty eggs, upon which the mother was sitting. I cut off the leaf, along with the eggs-upon which the mother jumped off-and placed them in a glass with some damp earth at the bottom. About the fourteenth day, having returned from an excursion, I found, at 9 A.MI, all the eggs hatched, and I remarked on the young ones a little white tail (see Fig. 2, c), which by the afternoon had altogether disappeared."

Dr. Gundlach's collection, as Dr. Peters tells us, contains four eggs of this frog, with embryos. They consist of a transparent vesicle of from 45 to 5.5 mill. in diameter, which is partly occupied by an opaque flaky white mass. The vesicle is filled with a trans. parent fluid, which allows one to see every part of the swimming embryo quite clearly. The embryo, as in the case of mammals, is curved together on the lower surface, so that the head approaches the lower extremities, which, as well as the anterior extremities, are drawn together under the belly and lie close to the body. 
The tail is likewise curved up underneath, and lies with its broad surface towards the body, turning either towards the right or the left, and thickening part of the hinder extremities. In three examples the extremities are fully developed, and even show the characteristic discs on the tops of the toes. In the fourth example all four extremities present short stumps, and as yet show no traces of toes, whereas, as is well known, in the Batrachia anura generally the hinder extremities and the ends of the feet first appear. Neither of branchice nor of branchial slits is there any trace. On the other hand, in the last-mentioned example, the tail is remarkably larger, and has its broad surface closely adberent to the inner wall of the vesicle, and very full of vessels, so that there can be no doubt of its function as a breathing organ. As development progresses, the yelk-bag on the belly and the tail become gradually smaller, so that at last, when the little animal, being about $5 \mathrm{mill}$. long, bursts through the envelope, the tail is only 1.8 mill. in length, and after a few hours only 0.3 mill. long, and in the course of the same day becomes entirely absorbed. Examples of the same batch of ova, which were placed in spirit eight days after their birth, have a length of from 70 to 7.5 mill, whence we may conclure that their growth is not quicker than in other species of Batracbians.

The development of this frog, Dr. Peters observes (and probably of all the nearly allied species), wilhout metamorphosi., without branchize, with contemporaneous evolution of the anterior and post rior extremities, as in the case of the higher vertebrates, and within a vesicle, like the amnion of these latter, if not strictly equivalent to it, is truly remarkable. But this kind of development is not quite unparalleled in the Batrachians, for it has long been known that the young of Pipa ameracana come forth from the eggs laid in the cells on their mother's back tailless and perfectly developed. In them, likewise, no one has yet detected branchize, and we also know from the observations of Camner, ${ }^{1}$ that the embryos ar an earlier period are provided with a tail-like appendage, which in this case also, may be perhaps regarded as an organ of breathing, possibly corresponding to the yelk-placenta of the hagfish. As regards this point, also, Laurenti says of the Pipa: "Pulli ex loculamentis dorsi prodeuntes, metamorThosi nulla?" (Sin. Rept, p. 25.)

It would be of the highest interest, Dr. Peters adds, to follow exactly this remarkable development on the spot The development of the embryo of these Batrachians in a way very like that of the scaled Reptilia makes one suspect that an examination of the temporary embryonic structures of Hylodes and Pipa would result in showing remarkable differences from those of other Batrachians. The general conclusions which might be drawn from this discovery are so obvious, says.Dr. Peters, in conclusion, that it would be superfluous to put them forward.

A subsequent communication of Dr. Peters to the Academy informs us that it had escaped his notice that M. Bavay, of Guadaloupe, had already published some observations on the development of Hylodes martinicensis." According to his observations, on each side of the heart there is a branchia consisting of one simple gill-arch, which on the seventh day is no longer discernible. On the ninth day there is no longer a trace of a tail, and on the tenth day the little animal emerges from the egg. M. Bavay also observed the contemporaneous development of the four extremities, and hints at the function of the tail as an organ of breathing.

The observations of Dr. Gundlach, therefore, says Dr. Peters, differ in some respects from those of M. Bavay. $r_{t}$ would be specially desirable, however, to ascertain whether tre arched vessel on each side of the heart is really to be regarded as a gill-arch, or only as the incipient bend of the aorta.

\footnotetext{
"Comm, Soz. Reg. Gotting. Cl. phys, ix p. r3s (2788).
}

Aun, Sc. Nat. ser, 5, xvin, art. No, $16(\mathrm{r} 873$.
TYPICAL LAWS OF HEREDITY 1

WE are far too apt to regard common events as matters of course, and to accept many things as obvious truths which are not obvious truths at all, but present problems of much interest. The problem to which I am about to direct attention is one of these.

Why is it when we compare two groups of persons selected at random from the same race, but belonging to different generations of it, we find them to be closely alike? Such statistical differences as there may be, are always to be ascribed to differences in the general conditions of their lives; with these I am not concerned at present, but so far as regards the processes of heredity alone, the resemblance of consecutive generations is a fact common to all forms of life.

In each generation there will be tall and short individuals, heavy and light, strong and weak, dark and pale, yet the proportions of the innumerable grades in which these several characteristics occur tends to be constant. The records of geological history afford striking evidences of this. Fossil remains of plants and animals may be dug out of strata at such different levels that thousands of generations must have intervened between the periods in which they lived, yet in large samples of such fossils we seek in vain for peculiarities which will distinguish one generation taken as a whole from another, the different sizes, marks and variations of every kind, occurring with equal frequency in both. The processes of heredity are found to be so wonderfully balanced and their equilibrium to be so stable, that they concur in maintaining a perfect statistical resemblance solong as the external conditions remain unaltered.

If there be any who are inclined to say there is no wonder in the matter, because each individual tends to leave his like behind him, and therefore each generation must resemble the one preceding, I can assure them that they utterly misunderstand the case. Individuals do not equally tend to leave their like behind them, as will be seen best from an extreme illustration.

Let us then consider the family history of widely different groups; say of 100 men, the most gigantic of their race and time, and the same number of medium men. Giants marry much more rarely than medium men, and when they do marry they have but few children. It is a matter of history that the more remarkable giants have left no issue at all. Consequently the offspring of the roo giants would be much fewer in number than those of the medium men. Again these few would, on the average, be of lower stature than their fathers for two reasons. First, their breed is almost sure to be diluted by marriage. Secondly, the progeny of all exceptional individuals tends to "revert" towards mediocrity. Consequently the children of the giant group would not only be very few but they would also be comparatively short. Even of these the taller ones would be the least likely to live, It is by no means the tallest men who best survive hardships, their circulation is apt to be languid and their constitution consumptive.

It is obvious. from this that the 100 giants will not leave behind them their quota in the next generation. The roo medium men, on the other hand, being more fertile, breeding more truly to their like, being better fitted to survive hardships, \&c., will leave more than their proportionate share of progeny. This being so, it might be expected that there would be ferver giants and more medium-sized men in the second generation than in the first. Yet, as a matter of fact, the giants and mediumsized men will, in the second generation, be found in the same proportions as before. The question, then, is this:- How is it that although each individual does not as a rule leave his like behind him, yet successive generations resemble each other with great exactitude in all their general features?

$x$ Lecture delivared at the Royal Institution, Friday evening, February g, by Francis Galton, If R.S. 